\title{
Distal Shower Embolization During Directional Coronary Atherectomy and Stenting for Diffuse Stenosis of Right Coronary Artery \\ Current Limitations of Intravascular Ultrasonography for Evaluating Fragile Plaque
}

\author{
Hidetsugu Sakai, MD; Kazushi Urasawa, MD; Naotsugu Oyama, MD; Akira Kitabatake, MD
}

\begin{abstract}
A 74 year-old male with old anterior and inferior myocardial infarctions was treated with staged percutaneous coronary intervention. A chronic total occlusion of the middle segment of the left anterior descending branch was successfully stented during the first stage, and during the second stage, preprocedural intravascular ultrasonography (IVUS) revealed that the proximal segment of the right coronary artery was diffusely stenosed by mixed plaque. Directional coronary atherectomy under IVUS guidance was performed, but coronary slow flow appeared during the procedure. After successfully bailing out with intracoronary nicorandil, percutaneous thrombectomy and manual blood pumping, 2 coronary stents were implanted to fully cover the lesion. Quite contrary to expectation, the no-reflow phenomenon appeared just after post-dilatation and a repeat of the same maneuver could not completely recover coronary flow. Plaque fragility could not be predicted from the IVUS examination. (Circ J 2004; 68: 257-262)
\end{abstract}

Key Words: Coronary intervention; Intracoronary imaging; Intravascular ultrasonography; No reflow phenomenon; Plaque

I ntravascular ultrasonography (IVUS) has been accepted as a useful tool for assessing target lesion plaque, selecting the most suitable strategy and deciding on the endpoint of a procedure. We report a patient with the complication of distal shower embolization both during directional coronary atherectomy (DCA) and just after stent implantation despite preprocedural IVUS images suggesting that the target plaque was solid enough to be treated with those devices. This is a rare case in which the current limitation of IVUS examination was manifested.

\section{Case Report}

A 74 year-old male with diabetes and a past history of smoking was admitted with symptoms of chest discomfort on effort. Seventeen years earlier, he suffered from an acute anterior myocardial infarction and ventricular septal perforation (VSP), which were successfully treated with left ventricular aneurysmectomy and VSP closure after conservative therapy. Despite careful follow-up, he again suffered an acute inferior myocardial infarction 5 years before the current admission and was treated medically.

Coronary angiography (CAG) revealed that the middle segment of the left anterior descending branch (LAD) was

(Received April 15, 2002; revised manuscript received July 15, 2002; accepted August 2, 2002)

Department of Cardiovascular Medicine, Hokkaido University Graduate School of Medicine, Sapporo, Japan

Mailing address: Kazushi Urasawa, MD, PhD, Department of Cardiovascular Medicine, Hokkaido University Graduate School of Medicine, Kita 15, Nishi 7, Kita-ku, Sapporo 060-8638, Japan. E-mail:

kazurasa@med.hokudai.ac.jp totally occluded and the proximal segment of the right coronary artery (RCA) was diffusely stenosed with poor collateral circulation to the LAD (Fig 1). We planned a
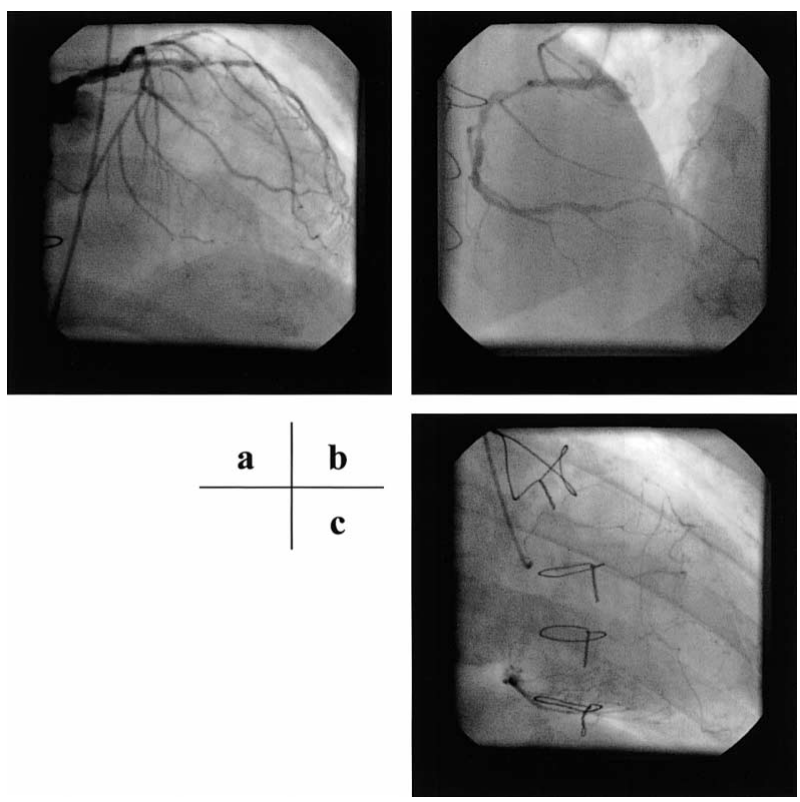

Fig 1. Diagnostic coronary angiography. (a) Left coronary artery from the antero-pesterior cranial view: the middle segment of the LAD is totally occluded. (b) RCA from the LAO cranial view showing diffuse stenosis of the proximal segment. (c) RCA has poor collateral circulation to the LAD. 
$\mathbf{a}$

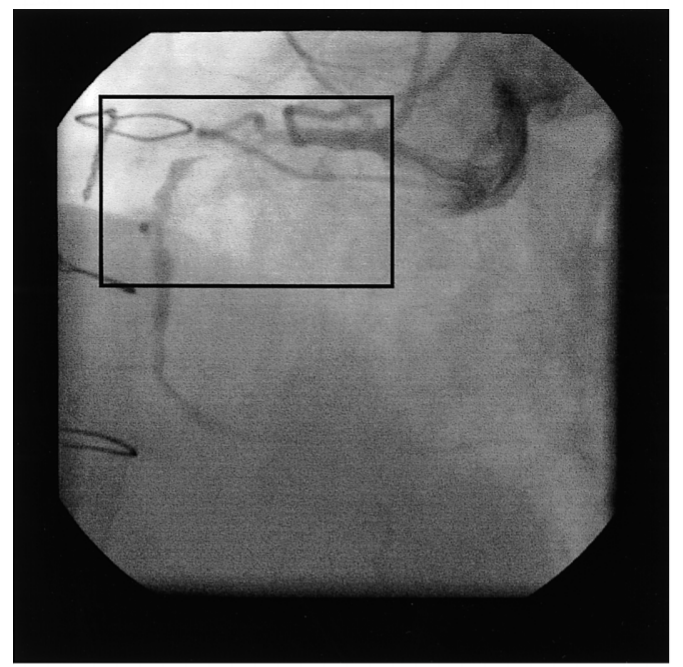

b
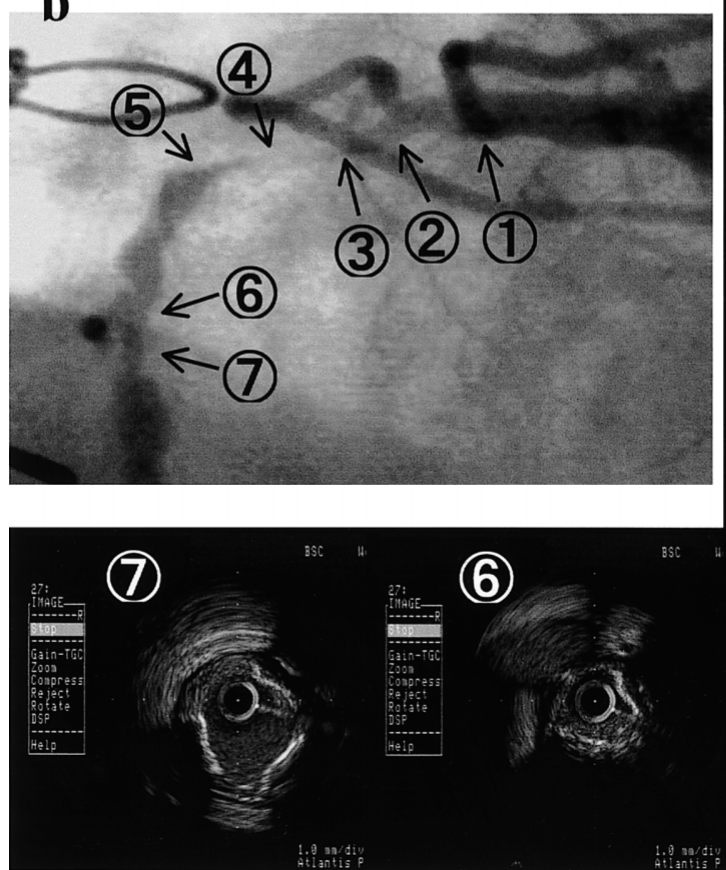

c

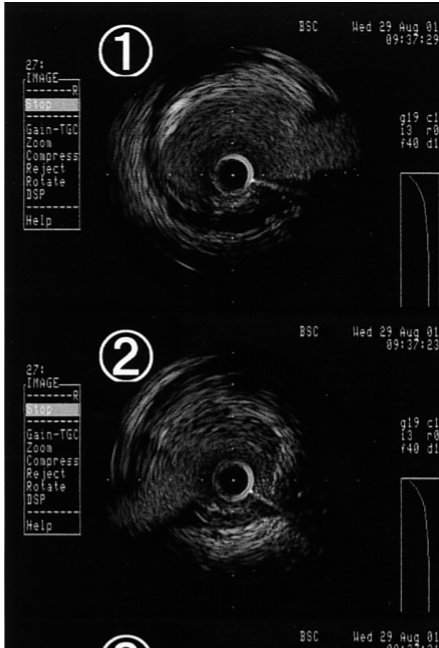

(3)
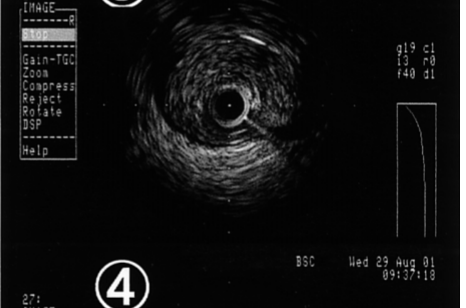

(4)

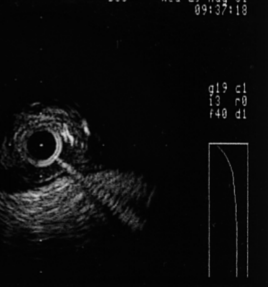

(5)

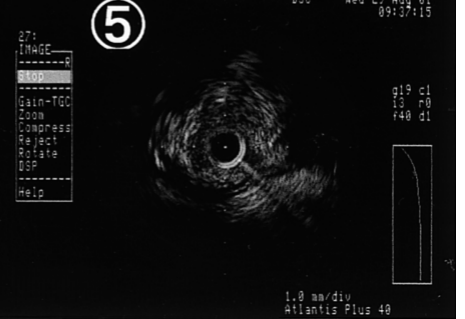

Fig 2. Preprocedural CAG and IVUS for the second stage PCI. (a) Preprocedural right CAG from the LAO view. The target lesion was exacerbated by delayed forward flow that was not recognized in the diagnostic angiography. (b) Magnification of the framed part of (a). (c) IVUS images. The number corresponds to those of the arrows in (b). A diffuse mixed fibrocalcified stenosis (3) (5) and a superficially calcified short stenosis (6)(7) were observed. The proximal mixed plaque was eccentrically distributed toward the major curvature.

staged percutaneous coronary intervention (PCI) for jeopardized multivessel disease in order to achieve complete revascularization.

A week later, the first stage of the PCI successfully dilated the chronic total occlusion of the mid LAD and a $3.0 \mathrm{~mm}$ Multilink-plus stent (Guidant) was implanted.

Another week later, he underwent the second stage. After insertion of a $10 \mathrm{Fr}$ catheter introducer, the patient was heparinized and the activated clotting time (ACT) was maintained above $300 \mathrm{~s}$ throughout the procedure. The RCA was engaged with a 6 Fr JR3.5 Zuma-II guiding catheter (Medtronic USCI) via the right femoral artery. The target lesion was easily crossed with a 0.014-inch Hitorque Balance Middle Weight guidewire (Guidant) and was examined with a $2.5 \mathrm{Fr}$ Atlantis SR plus imaging catheter (SciMed, Boston Scientific). On that basis, we planned DCA and provisional spot stenting because plaque quality was assumed to be mixed and less calcified (Fig 2c). A short lesion around the bifurcation of the right ventricular branch was superficially calcified, and simple stent placement was thought adequate for dilating this stenosis rather than DCA - stenting (Fig 2c). After the removal of all devices, the RCA was re-engaged with a 10 Fr JCR3.5 Tourguide guiding catheter (Guidant), and the lesion was easily crossed again with a 0.014-inch Neo's Gland-Slam guidewire of $300 \mathrm{~cm}$ length (Getz Bros). After making a small channel with a $2.0 \mathrm{~mm}$ Aerocross Fighter balloon catheter (Kaneka Corp), a 7 Fr-GTO Simpson Atherocath 
(Guidant) was advanced. Because the IVUS images suggested that the target plaque was eccentrically distributed toward the major curvature (Fig 2c), the atherocatheter was manipulated to turn its window upward, projecting from left anterior oblique view. The first 3 cuts with the directional balloon inflated at 10 psi were tentatively performed, rotating the atherocatheter clockwise by 45 degrees on the second cut and by the same degree counterclockwise for the third cut. The atherocatheter was removed leaving the long Neo's guidewire crossing the lesion because there was little resistance between the guidewire and the wire lumen of the atherocatheter. We found only a small amount of plaque debris in the nose cone and when debulked it looked white, suggesting that its quality was fibrous as indicated by the IVUS images. The atherocatheter was again advanced to the target lesion and manipulated in the same manner except for balloon pressure of 20 psi not 10 psi (Fig 3 ). The atherocatheter was pulled back into the guiding catheter, and the subsequent angiography showed slow flow phenomenon (Fig 4a). After removal of the atherocatheter, $2 \mathrm{mg}$ of nicorandil were transluminally injected and additional percutaneous thrombectomy with a 4.3 Fr Rescue-PT catheter (SciMed, Boston Scientific) and manual blood pumping for a few minutes recovered the coronary flow. Although a small dissection was detected at the debulked lesion on both angiography and IVUS (Fig 4b), antegrade

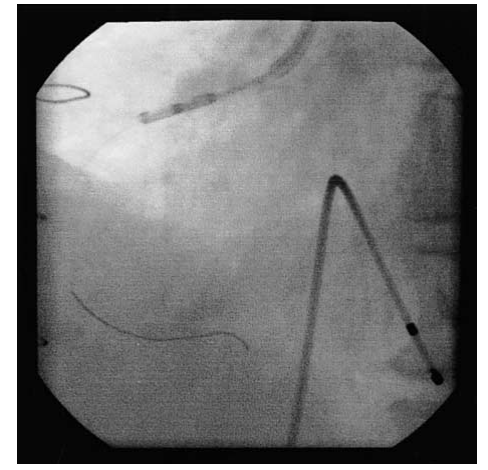

Fig 3. Directional atherectomy was performed to debulk the proximal stenosis, which corresponded to Fig 2c (2) (3)).

flow in the RCA began to be disturbed at the acute margin, not at the target lesion. The possibility that debulked plaque debris had dislodged from the gap in the guidewire lumen at the nose cone was weak because the atherocatheter was carefully manipulated and the resistance between the atherocatheter and guidewire had been low after the 20psi debulking. Collapse of fragile plaque that appeared solid on peprocedural IVUS images (Fig 2c) was considered to be the cause this complication, and dilatation of the a
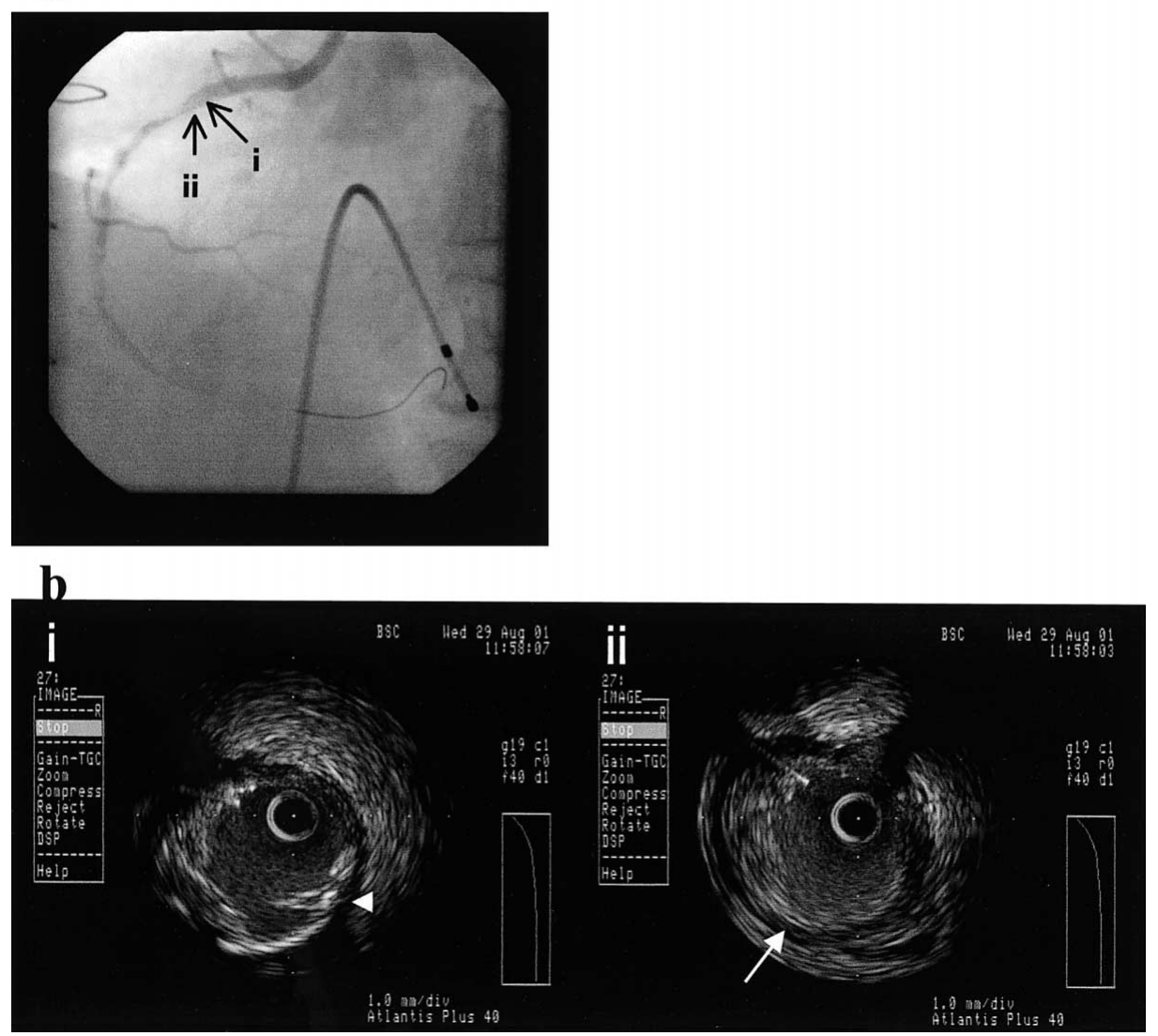

Fig 4. CAG and IVUS after 20-psi DCA. (a) CAG after 20-psi DCA. The proximal segment of the target lesion appeared to have been debulked, but the slow flow phenomenon appeared. (b) IVUS after restoring the impaired flow. Slices (i) and (ii) correspond to the proximal edge and the middle of the window of the atherocatheter, respectively. Preprocedural IVUS images of slices (i) and (ii) are shown in Fig 2c (2) and (3), respectively. In contrast to the angiographic findings, plaque volume reduction was insufficient (arrow). A small dissection newly appeared (arrowhead), but as it was small, it did not disturb the coronary flow. 


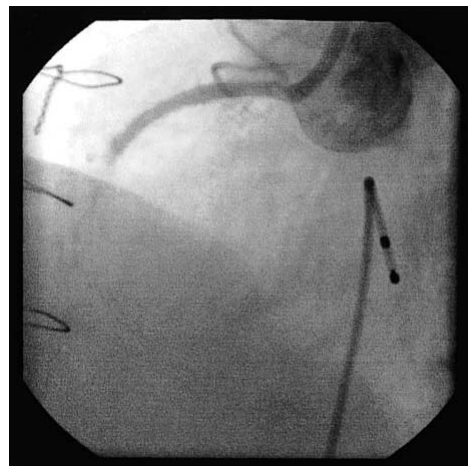

Fig 5. No reflow phenomenon after post-dilatation of the S670 stent. Distal runoff of contrast medium is completely lost. The cutoff sign is evident near the bifurcation of the right ventricular branch.

residual stenosis by stent placement was thought more appropriate treatment, on the expectation that stenting would improve forward flow and salvage coronary microcirculation. A $3.5 \mathrm{~mm}$ Multilink-plus stent (Guidant) and a $4.0 \times 24 \mathrm{~mm}$ S670 stent (Medtronic AVE) were deployed at the distal and proximal segments of the lesion, respectively, but the no-reflow phenomenon appeared quite unexpectedly just after post dilatation with the system balloon of the previous S670 stent (Fig 5). Distal shower embolization by a massive amount of plaque debris squeezed out between the stent struts was considered the cause of this serious complication. Transluminal injection of nicorandil, percutaneous thrombectomy and manual blood pumping were again performed, but could only restore the coronary flow to a mild slow-flow level (Fig 6a). Postprocedural IVUS images revealed that the plaque burden had significantly reduced compared with the preprocedural images (Fig 6b). Insufficient expansion of the S670 stent was also revealed, but we did not carry out supplementary high-pressure ballooning because of the risk of recurrence of impaired coronary flow. The risk of in-stent thrombosis was considered low because the struts were adhered closely to the vessel wall and the minimum stent diameter was over $3.0 \mathrm{~mm}$. A 9.5 Fr intraaortic counterpulsation catheter was inserted via his left femoral artery and he was transferred to the coronary care unit.

\section{Discussion}

The target lesion of the second stage of the present PCI was diffuse and the indications for and strategy of PCI for long or diffuse lesions are controversial. Although simple stenting without debulking has been reported as efficacious against long or diffuse stenosis, even in the setting of multiple short-stent implantations or single long-stent implantation, ${ }^{1,2}$ the fact that long or diffuse lesions belong to a sub-

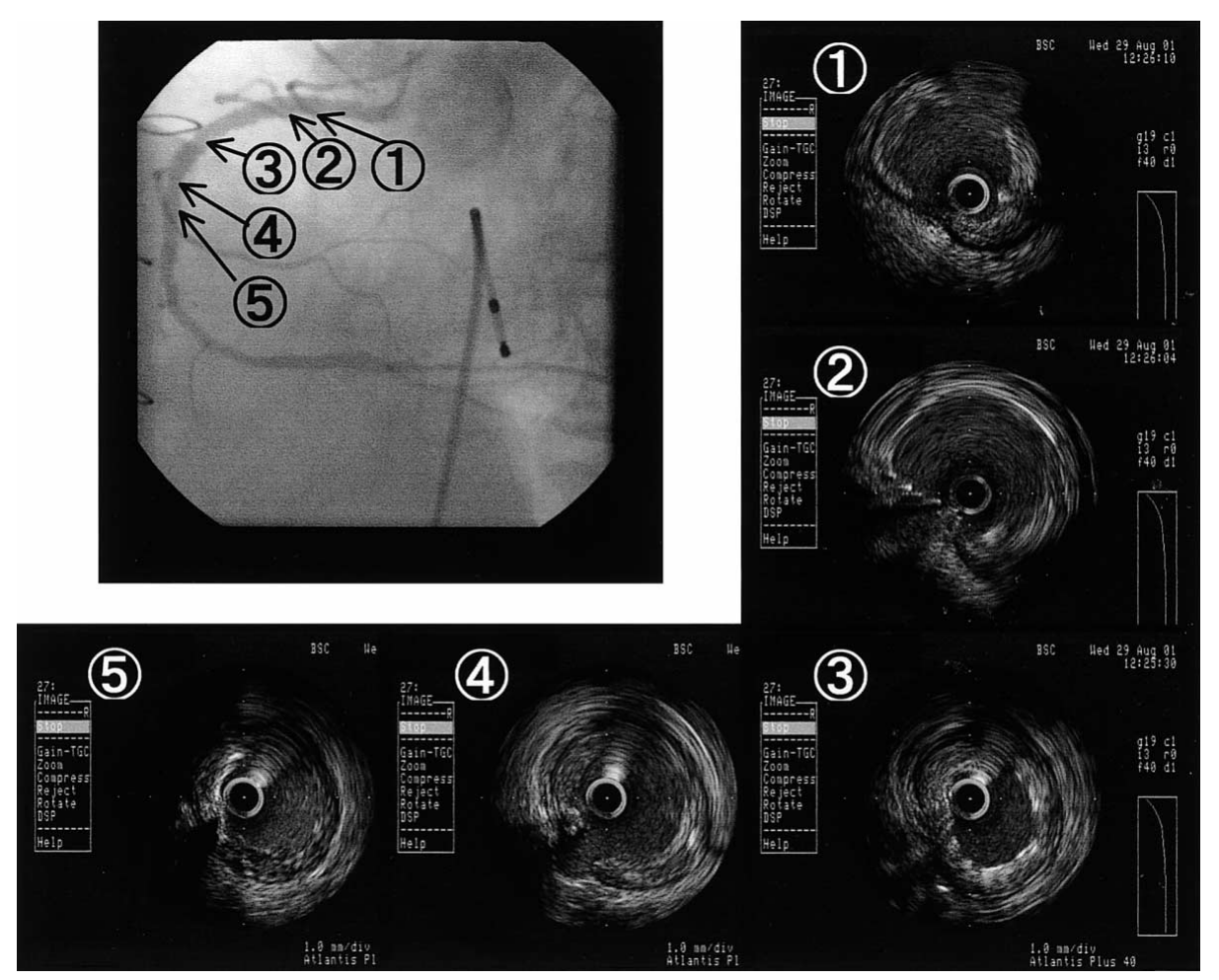

Fig 6. Final CAG and IVUS after ameliorating the no reflow phenomenon, which improved after intracoronary nicorandil, percutaneous thrombectomy and manual blood pumping, although there was residual slight flow disturbance. (Slice (1) An atrial branch arising from the proximal edge of a $4.0 \times 24 \mathrm{~mm} \mathrm{S670} \mathrm{stent.} \mathrm{(Slice} \mathrm{(2))} \mathrm{Bifurcation} \mathrm{of} \mathrm{a} \mathrm{right}$ ventricular branch. The S670 stent has eccentrically expanded, but the plaque burden outside the stent has significantly reduced despite insufficient debulking. (Slice (3)) The boundary point of a proximal S670 stent and a distal Multilink stent. This point was stenosed with fibrocalcified plaque (Fig 2c (4)(5)) and was not debulked before stent placement. Although the acute gain of this lesion was insufficient in contrast to the angiographic finding, additional high pressure ballooning was not performed for fear of a recurrence of impaired flow. (Slice (4)) Bifurcation of the right ventricular branch inside the distal Multilink stent. (Slice (5)) Distal edge of the Multilink stent, which was well expanded although the lesion was originally stenosed with an almost circular calcification (Fig 2c (6) (7)). 
group with high risk is unchanged? Moussa et al reported that reduction of plaque burden with IVUS-guided DCA prior to stenting was safe and had a good restenosis rate, but they excluded complex lesions such as in small or intermediate vessels, chronic total occlusions (CTO) and long lesions. Although the preliminary reports of the AMIGO study (Atherectomy before Multilink stent Improves Gain and clinical Outcomes) showed that DCA prior to stenting did not have a clear superiority to simple stenting without plaque volume reduction, patients who had optimal atherectomy were in the minority in that study. The ADAPTAS study, which used a non-randomized design, showed the efficacy of plaque volume reduction with directional atherectomy prior to stent placement in complex lesions such as CTO, ostial disease or long lesions? Moreover, the preprocedural plaque volume of the target lesion positively correlates with restenosis in the settings of stent placement, even in those cases of intracoronary radiation therapy after balloon angioplasty? Based on these reports, our strategy for reducing plaque burden as much as possible with directional atherectomy and not implanting long stents was thought acceptable.

The risk of distal embolization is high, especially in degenerated saphenous vein grafts $(\mathrm{SVG})$, with the no-reflow phenomenon being reported in up to $7.9 \%$ of cases, even without thrombus? Several kinds of covered stent are commercially available and one recently proved to be effective in reducing SVG flow impairment?,10 Although the target lesion in the present case was located in a native coronary artery, simple implantation of a coronary stent graft might have been a therapeutic option. In cases of acute coronary syndrome (ACS), this phenomenon also occurs with considerable frequency even in native coronary arteries!11,12 However, the frequency of embolized debris in routine PCI of native vessel has not been evaluated. The first clinical results of the effectiveness and safety of the AngioGuard Emboli Capture Guidewire (Cordis, Johnson and Johnson) was recently reported in a study by Eberhard et $\mathrm{al}^{13}$ in which not only 11 SVG lesions, but also 15 native vessel lesions were enrolled and all cases were electively treated. Surprisingly, there were particles with a mean size of $0.10 \pm 0.5 \mathrm{~mm}^{2}$ and a range of $0.015-20 \mathrm{~mm}^{2}$ in the filter basket and capture sheath of all cases. Therefore, there is a risk of distal embolization even with PCI in a native vessel, although the relationship between cardiovascular imaging and plaque fragility that will probably lead to distal embolization has yet to be elucidated fully.

In the setting of PCI for ACS, unstable or vulnerable plaques with sonolucent echogenicity are often found in an IVUS study. If conventional balloon angioplasty is performed for treatment of such lesions, distal embolization by atheromatous debris or intracoronary thrombus is often complicated and may lead to ischemic complications. Mixed fibrocalcific plaques such as in the present case do not appear to be destroyed by balloon compression, but in our case distal shower embolization was a quite unexpected complication. We used a $40 \mathrm{MHz}$ transducer for the IVUS assessment because, compared with the conventional $20-30 \mathrm{MHz}$ transducers, the high frequency IVUS transducers have been reported by Prati et al to be more effective in identifying lipid/necrotic pools in atherosclerotic plaques ${ }^{14}$ In that study, lipid pools were observed by histology in 30 sections, but IVUS with a $40-\mathrm{MHz}$ transducer revealed the presence of lipid pools in only 19 of them, so it must be emphasized that not all unstable plaques are detected during IVUS examination.

The present case may be in a minority subgroup in which IVUS cannot provide precise information. Optical coherence tomography (OCT) is a new modality for highresolution, cross-sectional, intravascular imaging. ${ }^{15}$ IVUS is currently of little use in determining the stability of subendothelial plaque components because of its limited resolution ( $>100 \mu \mathrm{m}$ even for $40 \mathrm{MHz}$ systems) and the confounding influence of surrounding tissues ${ }^{16}$ If IVUS systems become available with a $50 \mathrm{MHz}$ transducer, the maximum resolution will still be no greater than $70 \mu \mathrm{m} !^{17} \mathrm{In}$ contrast, the maximum resolution of OCT is limited physically only by the diffraction limit of light at $1,300 \mathrm{~nm}$, which is $<100 \mathrm{~nm}$, and systems are already available with axial resolutions less than $4 \mu \mathrm{m} !^{18}$ Such systems may ultimately be of use in cardiology for the identification of subcellular structures 19 and in fact, postmortem examination of human coronary arteries has shown that catheterbased OCT systems give superior delineation of vessel layers and lack of the ring-down artifact with higher resolution than a $30 \mathrm{MHz}$ IVUS system.18 The greatest limitation of OCT is its reduced effectiveness when imaging through blood ${ }^{20}$ which also applies to Raman spectroscopy and near-infrared spectroscopy 11,22 Although index matching through blood (ie, increasing the refractive index of serum to a value near that of the erythrocyte cytoplasm by dextran or intravenous contrast agent infusion) was reported to reduce scattering and to improve OCT images, it is not known which compound is the most effective for index matching in vivo?3 We can look forward to new imaging systems with higher resolution, but at present IVUS is the only available tool for detecting and evaluating atherosclerotic plaques.

The mechanism of the no-reflow phenomenon is probably multifactorial and involves small-vessel vasospasm and potentially platelet-mediated loss of capillary autoregulation? 24,25 In the setting of PCI for acute myocardial infarction, endothelial damage, including endothelial swelling and myocyte edema, leads to initial no reflow zones, and additional edema, myocyte contraction, platelets, fibrin and leukocyte plugging result in expansion of the no reflow zones with reperfusion. ${ }^{26}$ However, in the setting PCI of routine native vessel such as in the present case, initial embolization of the atheromatous debris, as well as blood clots and platelet plugs, seems to have been the trigger for the cascade of events that lead to microvascular vasoconstriction.27 In particular, several investigators have suggested that platelet activation plays a pivotal role in this cascade and so the use of glycoprotein IIb/IIIa inhibitors might improve distal runoff. 28

A variety of new, innovative devices for distal protection are now in clinical studies and the research phase, and have proven to be effective in preventing impaired flow during catheter therapies!3,29,30 The introduction of these devices, as well as more potent antiplatelet agents, into real clinical settings will help reduce the incidence of impaired coronary flow during catheter interventions. However, precise preprocedural assessment with intracoronary imaging of plaque fragility that could lead to distal embolization systems is most essential.

\section{Conclusion}

IVUS assessment is essential for safe PCI. In most cases the images are consistent with histopathological findings, 
but it should not be ignored that there are a small number of cases in which that principle cannot be applied. New intravascular imaging systems with higher resolution and less artifacts will improve both detection and evaluation of atherosclerotic plaques before interventional procedures, and new antiplatelet agents and distal protection devices are expected to reduce the no reflow phenomenon.

\section{References}

1. Kornowski R, Mehran R, Hong MK, Saler LF, Pichard AD, Kent $\mathrm{KM}$, et al. Procedural results and late clinical outcomes after placement of three or more stents in single coronary lesions. Circulation 1998; 97: 1355-1361.

2. Kornowski R, Bhargava B, Fuchs S, Lansky AJ, Satler LF, Pichard $\mathrm{AD}$, et al. Procedural results and late outcomes after percutaneous interventions using long $(\geq 25 \mathrm{~mm})$ versus short $(<20 \mathrm{~mm})$ stents. $J$ Am Coll Cardiol 2000; 35: 612-618.

3. Smith SC Jr, Dove JT, Jacobs AK, Kennedy JW, Keriakes D, Kern $\mathrm{MJ}$, et al. ACC/AHA guidelines for percutaneous coronary intervention (revision of the 1993 PTCA guidelines)-executive summary: A report of the American College of Cardiology/American Heart Association task force on practice guidelines (Committee to revise the 1993 guidelines for percutaneous transluminal coronary angioplasty) endorsed by the Society for Cardiac Angioplasty and Interventions. Circulation 2001; 103: 3019-3041.

4. Moussa I, Moses J, Di Mario C, Busi G, Reimers B, Kobayashi Y, et al. Stenting after optimal lesion debulking (SOLD) registry: Angiographic and clinical outcome. Circulation 1998; 98: 1604-1609.

5. Kiesz RS, Rozek MM, Mego DM, Patel V, Ebersole DG, Chilton RJ. Acute directional coronary atherectomy prior to stenting in complex coronary lesions: ADAPTAS study. Cathet Cardiovasc Diagn 1998; 45: $113-114$.

6. Prati F, Di Mario C, Moussa I, Reimers B, Mallus MT, Parma A, et al. In-stent neointimal proliferation correlates with the amount of residual plaque burden outside the stent: An intravascular ultrasound study. Circulation 1999; 99: 1011-1014.

7. Sabate M, Marijnissen JP, Carlier SG, Kay IP, van der Giessen WJ, Coen VL, et al. Residual plaque burden, delivered dose, and tissue composition predict 6-month outcome after balloon angioplasty and beta-radiation therapy. Circulation 2000; 101: 2472-2477.

8. Lefkovits J, Holmes DR, Califf R, Safian RD, Pieper K, Keeler G, et al. Predictors and sequelae of distal embolization during saphenous vein graft intervention from the CAVEAT-II trial. Circulation 1995; 92: $734-740$.

9. Briguori C, De Gregorio J, Nishida T, Adamian M, Albiero R, Tucci $\mathrm{G}$, et al. Polytetrafluoroethylene-covered stent for the treatment of narrowing in aorticocoronary saphenous vein graft. Am J Cardiol 2000; 86: $343-346$

10. Baldus S, Koester R, Elsner M, Walter DH, Arnold R, Auch-Schwelk $\mathrm{W}$, et al. Treatment of aortocoronary vein graft lesions with membrane-covered stents. Circulation 2000; 102: 2024-2027.

11. Cameron J, Buchbinder M, Wexler L, Oesterle SN. Thromboembolic complications of percutaneous transluminal coronary angioplasty for myocardial infarction. Cathet Cardiovasc Diagn 1987; 13: $100-$ 106.

12. Ishibashi F, Saito T, Hokimoto S, Noda K, Moriyama Y, Oshima S. Combined revascularization strategy for acute myocardial infarction in patients with intracoronary thrombus: Preceding intracoronary thrombolysis and subsequent mechanical angioplasty. Jpn Circ J 2001; 65: 251-256.

13. Grube E, Gerckens U, Yeung AC, Rowold S, Kirchhof N, Sedgewick $\mathrm{J}$, et al. Prevention of distal embolization during coronary angioplasty in saphenous vein grafts and native vessels using porous filter protection. Circulation 2001; 104: 2436-2441.

14. Prati F, Arbustini E, Labellarte A, Dal Bello B, Sommariva L, Mallus MT, et al. Correlation between high frequency intravascular ultrasound and histomorphology in human coronary arteries. Heart 2001; 85: 567-570.

15. Huang D, Swanson EA, Lin CP, Schuman JS, Stinson WG, Chang W, et al. Optical coherence tomography. Science 1991; 254: $1178-$ 1181.

16. Peters RJG, Kok WEM, Havenith MG, Rijsterborgh $\mathrm{H}$, van der Wal AC, Visser CA. Histopathologic validation of intracoronary ultrasound imaging. J Am Soc Echocardiogr 1994; 7: 230-241.

17. Foster FS, Knapik DA, Machado JC, Ryan LK, Nissen SE. High-frequency intracoronary ultrasound imaging. Semin Intervent Cardiol 1997; 2: 33-41.

18. Patwari P, Weissman NJ, Boppart SA, Jesser C, Stamper D, Fujimoto JG, et al. Assessment of coronary plaque with optical coherence tomography and high-frequency ultrasound. Am J Cardiol 2000; 85: 641-644.

19. Boppart SA, Bouma BE, Pitris C, Southern JF, Brezinski ME, Fujimoto JG. In vivo subcellular optical coherence tomography imaging in Xenopus laevis: Implications for the early diagnosis of neoplasms. Nat Med 1998; 4: 861-865.

20. Fujimoto JG, Boppart SA, Tearney GJ, Bouma BE, Pitris C, Brezinski ME. High resolution in vivo intraarterial imaging with optical coherence tomography. Heart 1999; 82: 128-133.

21. Kern MJ, Meier B. Evaluation of the culprit plaque and the physiological significance of coronary atherosclerotic narrowings. Circulation 2001; 103: 3142-3149.

22. Fayad ZA, Fuster V. Clinical imaging of the high-risk or vulnerable atherosclerotic plaque. Circ Res 2001; 89: 305-316.

23. Brezinski ME, Saunders K, Jesser C, Li X, Fujimoto JG. Index matching to improve optical coherence tomography imaging through blood. Circulation 2001; 103: 1999-2003.

24. Lotan C, Shaohong D. The no-reflow phenomenon: A light at the end of the tunnel? Cathet Cardiovasc Interv 2000; 51: 400-401.

25. Noguchi T, Nonogi H, Yasuda S, Daikoku S, Morii I, Itoh A, et al. Refractory coronary spasm relieved by intracoronary administration of nicorandil. Jpn Circ J 2000; 64: 396-398.

26. Rezkalla SH, Kloner RA. No-reflow phenomenon. Circulation 2002; 105: $656-662$

27. Kloner RA. No reflow revisited. J Am Coll Cardiol 1989; 14: 18141815.

28. Rawitscher D, Levin TN, Cohen I, Feldman T. Rapid reversal of noreflow using abciximab after coronary device intervention. Cathet Cardiovasc Diagn 1997; 42: 187-190.

29. Carlino M, De Gregorio J, Di Mario C, Anzuini A, Airoldi F, AlbieroR, et al. Prevention of distal embolization during saphenous vein graft lesion angioplasty: Experience with a new temporary occlusion and aspiration system. Circulation 1999; 99: 3221-3223.

30. Baim DS, Wahr D, George B, Leon MB, Greenberg J, Cutlip DE, et al. Randomized trial of a distal embolic protection device during percutaneous intervention of saphenous vein aorto-coronary bypass grafts. Circulation 2002; 105: 1285-1290. 